


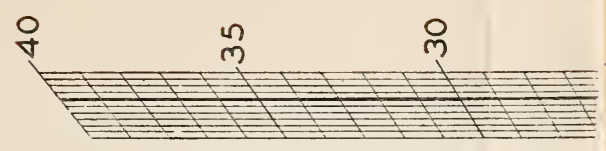

These charts were de etric observations and al idition of two scales per le customary double inte: ad halved the time requ

To use either chart, ] ifference between wet- a et-bulb temperature. $\mathrm{E}$ le barometric pressure, a icludes all necessary corr

Suppose a psychrometer $r$ ad the pressure of water vapo i that it meets the "wet bulb, heavy vertical line marked 7 rmula gives $11.486 \mathrm{~mm} \mathrm{Hg}$.

To determine the rela ) the corresponding poi $76 \mathrm{~cm}$ on the centigrade oint representing the $\mathrm{dr}$ , its intersection with th

Continuing the example st $\mathrm{g}$ pressure of water vapor, a ulb, "C." By extending thi stained, reading the "Relatir om 0 at the top to 100 at thi

In obtaining the press Wet Bulb" is employe [nwever. more accurate.
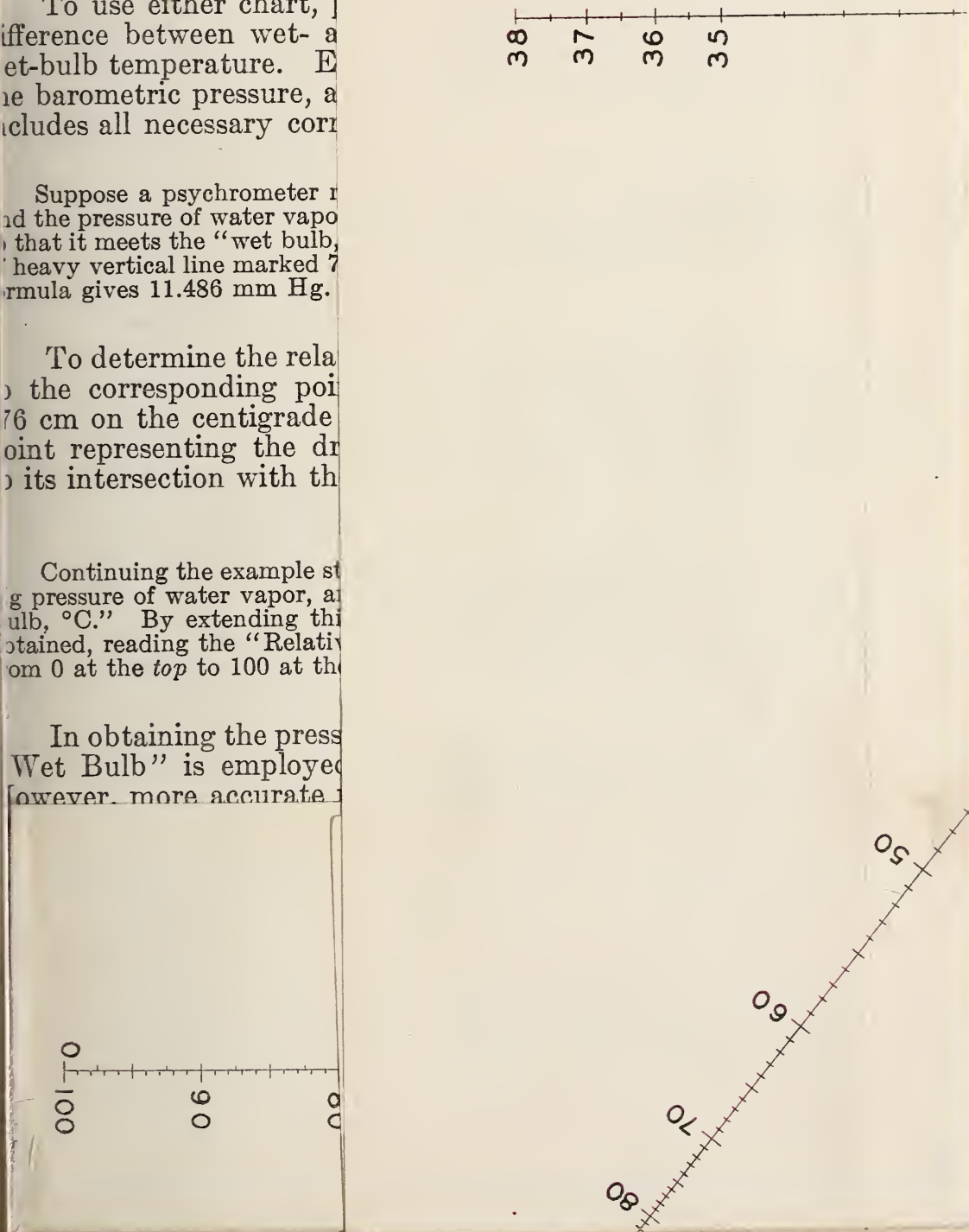



\title{
PSYCHROMETRIC CHARTS
}

\author{
By Donald B. Brooks
}

These charts were developed for use in the determination of the pressure of water vapor from psychrometric observations and are based on the psychrometric formula. In their development it was found that the addition of two scales permitted the acenrato evaluation of relative humidity as well. In comparison with the customary double interpolation tables it has been found that tho use of these charts inereased the precision and halved the time required.

To 450 either chart, place a straightedge so that it intersects the extreme left seale at the valuc of the differenee betwcen wet- and dry-bulb temperatures, and intersects the wet-bulb seale at the value of the wet-bulb temperature. Extend this line to the right to its intersection with the rertieal line which represents the barometrie pressure, and read the pressure of watcr vapor on the seale at the cxtreme right. This value includes all necessary eorrections.

\section{Exasiple (Centigrade Chart)}

Suppose a psychroneter reads $35^{\circ} \mathrm{C}$. on the dry bulb and $21^{\circ} \mathrm{C}$, on the wet bulb when the barometer in $77 \mathrm{~cm} \mathrm{Hg}$. To find the pressure of water vapor, place a ruler so that it intersects the "dry bulb minus wet bulb, ${ }^{\circ} \mathrm{C}$ " $5 c a l e$ at $35-21=14$. Adjust so that it meets the "wet bulb, $\mathrm{C}$ " Ecalc at $2 \mathrm{I}$, and note the point at which it intorscets the $77 \mathrm{~cm}$ barometer line (first line right of hesyy vertical lino marked 76); the value of the humidity so obtained is II.5 inm lig. A computatian from the psychrometric formula gives 11.486 ma $\mathrm{Hg}$.

'To detcrmine the relative lumidity, trausfer the value of the pressure of water vapor obtained as described to the corrcsponding point on tho central heavy vertical line representing standard barometrie pressure ( $76 \mathrm{~cm}$ on the eentigrade chart, $30 \mathrm{in}$. on that for Fralurenheit). Conneet by straightedge this point and the peint representing the dry-bulb temperature on the diagonal line marked "Dry Bulb." Extend the line to its interscetion with the vertical line on tho left, and read relative humidity on the inner left scalc.

\section{Exasple (Centigrade Clart)}

Continuing the example started above, loeste the point on the heavy vertical 70 cra barometer line whieh represeuts 11.5 mm $\mathrm{Hg}$ pressure of Fnter vapor, and connect this poiut with the point at $35^{\circ} \mathrm{C}$., near the middle of the diagonal line marhed "Dry Bulb "C." By extending this line to its intersection with the vertical lino at the left the valne $27.2 \%$ relative humidity is obtsined, readiug the "Relative Humidity, percent" geale on the inner side of the left vertical line. Note that this scale reads from 0 at the top to 100 at the bottom. By computation, the relative liumidity for the example selected is found ta be $27.20 \%$.

In obtaining the pressure of water vapor when the wet-bulb temperature is below freezing, the scalo marked "Wet Bulb" is employed if tho psyclurometer was used with either supercoolcd water or a frozen wick. Howerer, moro accurate results can bo obtained with an icc-coated thermometer, and the "Ice Bulb" scale (te the right of the "Wet Bulb" scale) is used in place of tho "Wet Bulb" seale.

The Fahrenheit chart is based on Professor Ferrcl's psychrometrie formula, whicb is used in the United States Weathor Burcau's Psychrometric Tables.t This formula is

Es:

$$
c=e^{\prime}-0.000367 P\left(t-t^{\prime}\right)\left(1+\frac{t^{\prime}-32}{1571}\right)
$$

in which $t$ and $t^{\prime}$ are the temperatures of tho dry-and wot-hulb themometers, in degrees Fahrenheit; $P$ is the barometrie pressure at the psyebrometer, in inehes of mereury; $e^{\prime}$ is the saturation pressure of water vapor in inches of mereury at the tomperature $t^{\prime}$ of the wet bulb; and $e$ is the atmospheric humidity in incbes of mereury.

The eentigrade chert is based on the analogous formula

$$
e=e^{\prime}-0.000652 P\left(i-t^{\prime}\right)\left(1+0.00102 t^{\prime}\right)
$$

in which $P$, $e^{\prime}$, and $e$ are oxpressed in millimeters of mercury, and $t$ and $t^{\prime}$ in degrces centigrade. The constnots ised in this formul are based on reeent data, ${ }^{23}$ which are believed to bo inoro acenrate, rather then on the alues corresponding to those used by the United States Weather Bureau, and employed in constructing the ahrenheit ehart, whieh would be 0.000660 and 0.00115 , respectivcly. The two eharts will not agrce exactly; pwever, the differenee will obviously be of the order of the experimental error.

1Psychromatric Tebles, W, B NO. 23s, $10 \mathrm{csnts}$

PFechtigkelesmessugg, by Dr. Hermano Bongards.

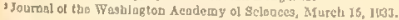



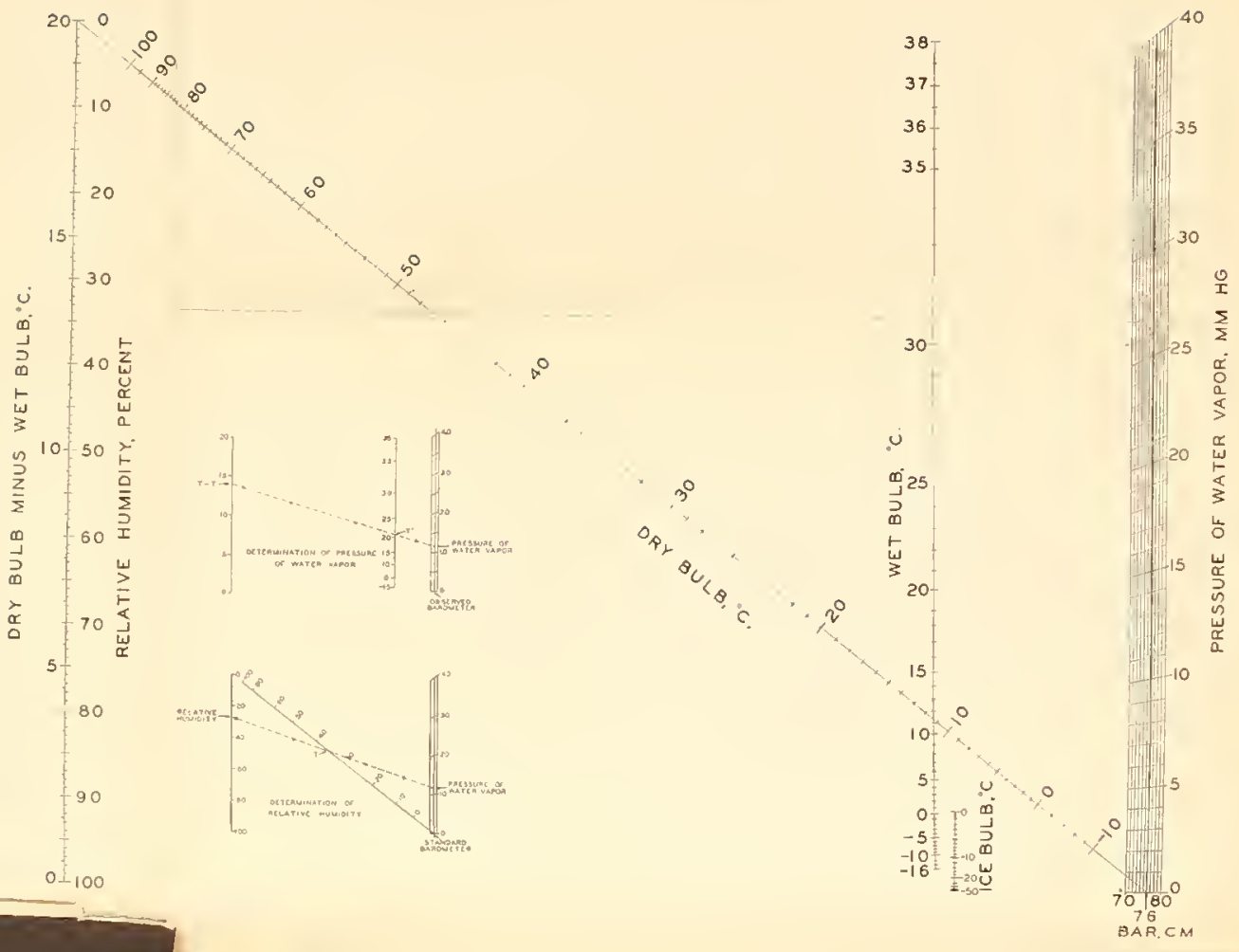

W ' $\operatorname{dod} \forall \wedge$ $\forall \exists \perp \forall M$ JO $\exists$ ynss $\exists y d$

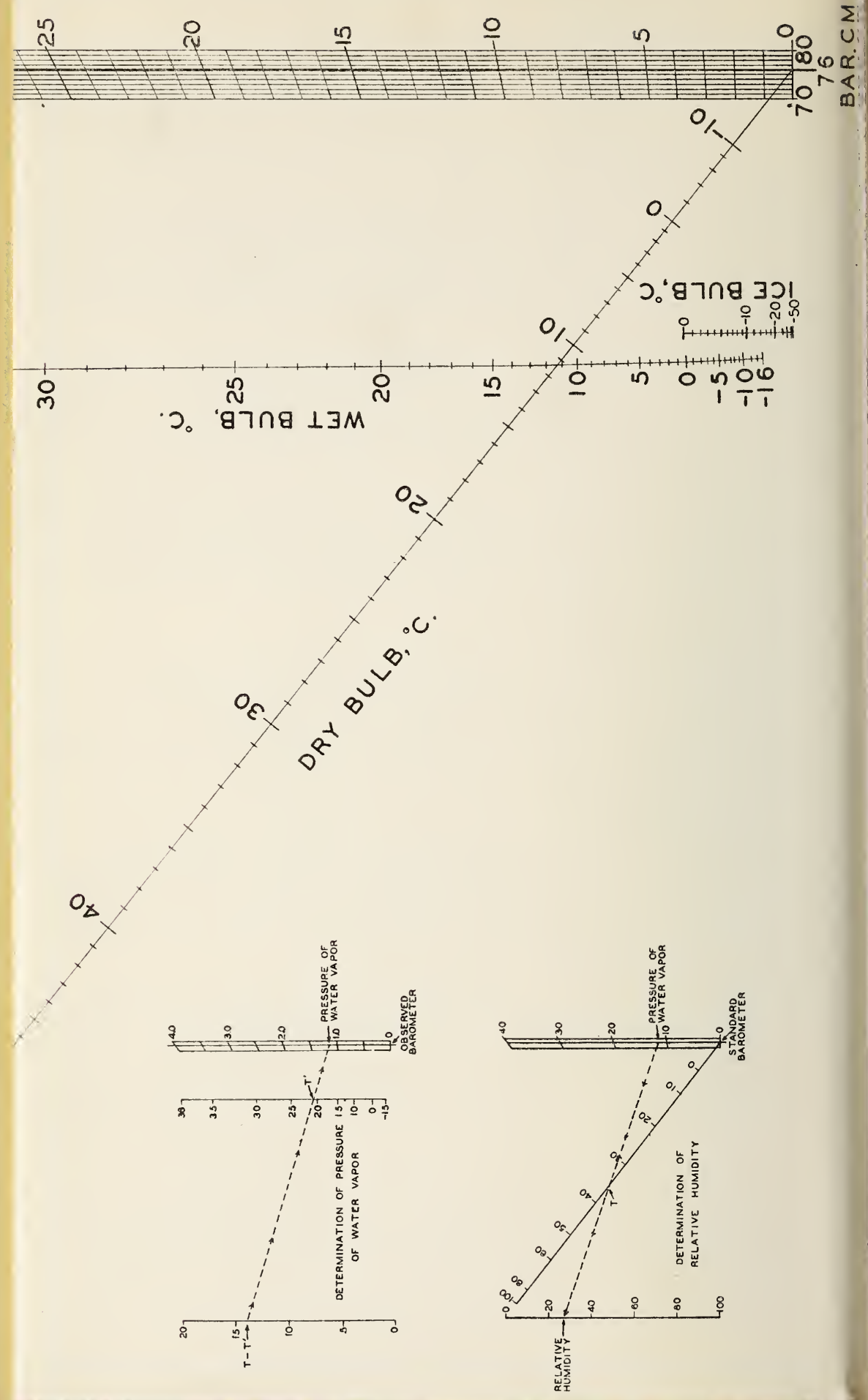





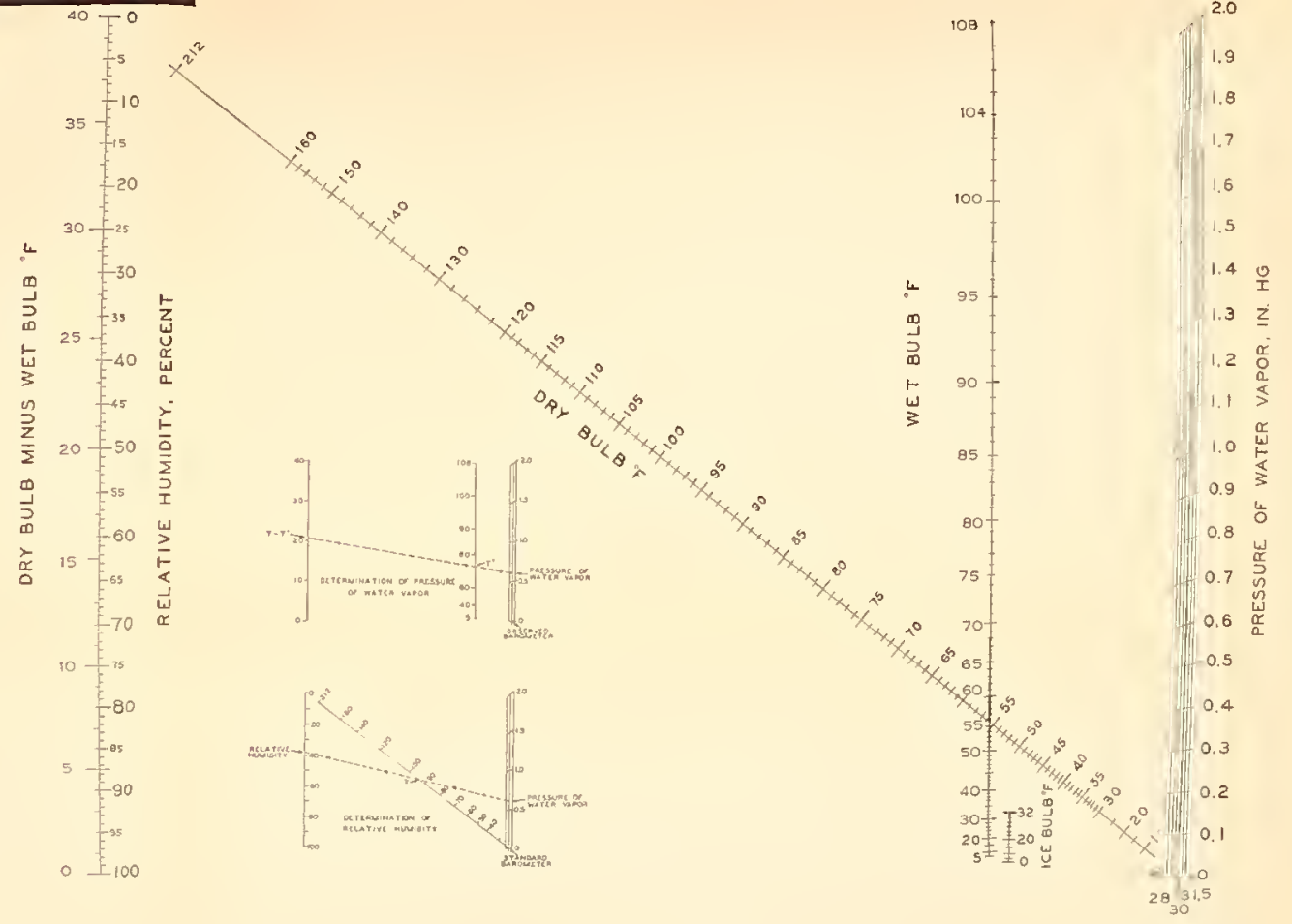

GAROMFTFA 
兲 